\title{
FIQH VERSI ALAM MELAYU: SATU ANALISIS SEJARAH
}

\section{The Malay World Version of Fiqh: A Historical Analysis}

\author{
Rahimin Affandi Abdul Rahim * \\ Siti Maimunah Kahal ** \\ Muhammad Yusri Yusof @ Salleh ***
}

\begin{abstract}
This study discusses how Islam became the most important episode in the history of the Malay World. The arrival of Islam that had modified the world view of Arab communities in the Arab World brought about the same changes to the Malay World. The Islamisation process resulted in knowledge development which produced paradigms vialable for Malay society. The basic traditions formulated by Islamic theologians in the $16^{\text {th }}-18^{\text {th }}$ centuries has become the core foundation for the Islamic Malay World until today. This is a theory from Middle East figh that has been changed to suit the culture and identities of the Malay World and as the guidance of life for the Malay community. The various Malay World fiqh sources have made it to become unique
\end{abstract}

* Assoc. Prof. at Department of Fiqh and Usul, Academy of Islamic Studies, University of Malaya, faqir_ila_rabbih@um.edu.my

** Postgraduate Student at Department of Fiqh and Usul, Academy of Islamic Studies, University of Malaya, mykahal89@yahoo.com

*** Postgraduate Student at Department of Fiqh and Usul, Academy of Islamic Studies, University of Malaya. 
and very special and this study pays particular reference to the Malay World Figh. Thus, this version of Fiqh is analyzed based on the history of the Malay World with its abundant Islamic knowledge that emerged from the process of Islamisation. The analysis shows that Islamisation has produced a Malay World version of fiqh as an important channel in the creation of knowledge and characteristics of the community and has contributed to the rapid development of Islam.

Keywords: Fiqh, Malay World, Malay Islamisation, Malay World History

\section{PENGENALAN}

Hukum Islam adalah bersifat progresif dilihat kepada kaitannya dengan perkembangan masyarakat. Ini kerana hukum Islam timbul dari realiti sebenar dan hasil respon fuqaha terhadap apa yang berlaku di dalam masyarakat. Lebih tepat lagi, ia bukan dibuat secara ramalan semata-mata ataupun daripada ruang yang hampa (innihilo). ${ }^{1}$ Memandangkan perkembangan sesuatu masyarakat itu sentiasa bersifat dinamik dan kerap berubah seiring dengan perubahan waktu, ruang, keadaan, tradisi and motivasi; hukum Islam secara automatik perlu mengikut elemen-elemen perubahan ini secara berhemah. ${ }^{2}$

Bagi memperincikan prinsip dinamisme dan perubahan hukum Islam ini, kita perlu melihatnya dengan memberikan penekanan kepada beberapa aspek-aspek yang pasti timbul selaras dengan perubahan masyarakat, aspek waktu, ruang, keadaan, tradisi dan motivasi. Bagi prinsip waktu ini, Yūsuf al-Qaraḍ̄̄̄ī menegaskan bahawa fuqaha Islam tidak boleh secara kaku dan jumud menetapkan hukum bagi sesuatu masalah hanya untuk

1 Mujiyono Abdillah, Dialektika Hukum Islam dan Perubahan Social: Sebuah Refleksi Sosiologis atas Pemikiran Ibn Qayyim Al-Jauziyyah (Surakarta: Muhammadiyah University, 2003), 1-3.

2 Saleh Faghizadeh, Sosiologi Sosiologi, terj. Mohd Fauzi Yaacob (Kuala Lumpur: ITNMB, 2004). 
waktu tertentu. ${ }^{3}$ Ini kerana, sebahagian hukum Islam adalah hasil usaha ijtihad fuqaha tertentu yang ditetapkan berasaskan kepada mașlahah pada waktu yang tersendiri - sudah pasti ia berbeza dengan ruang waktu fuqaha pada zaman terkemudian.

Oleh itu, berasaskan kepada latar belakang ini, kajian ini akan cuba memperincikan sistem fiqh versi Alam Melayu yang wujud pada abad ke 16-18. Pihak penulis berpendapat bahawa era abad ini merupakan era terpenting dalam sejarah perkembangan hukum Islam di Alam Melayu.

\section{ABAD KE-16 SEBAGAI ERA FORMATIF KEILMUAN ISLAM ALAM MELAYU}

'Ābid Jābirīi telah menegaskan bahawa zaman sahabat sehingga Imam Mujtahid merupakan zaman formatif untuk sistem Fiqh Islam, yang menetapkan asas metodologi hukum Islam; maka di Alam Melayu era formatif untuk keseluruhan ilmu-ilmu Islam adalah pada era abad ke 16-18. Bermula pada era asas inilah pelbagai ilmu Islam telah berkembang dengan pesat. Intipati penting daripada pandangan ini adalah keilmuan Islam berpunca daripada pemahaman terhadap sumber Islam sendiri, dan bukannya hasil peniruan daripada sumber dan tamadun asing, seperti mana yang ditegaskan oleh sarjana orientalis. ${ }^{5}$

Kenyataan ini disokong oleh hujah berikut;

1. Seperti mana kedatangan Islam telah mengangkat martabat dan mentamadunkan bangsa Arab, hal yang sama berlaku kepada umat Melayu-Islam. Dalam banyak aspek, Islam telah memperkenalkan world-view tauhid dan budaya ilmu kepada masyarakat Melayu. World-view adalah pandangan dunia, hidup, kepercayaan dan pemikiran yang berfungsi sebagai

3 Yūsuf al-Qaraḍāwī, Madkhal li Dirāsah al-Syarī'ah al-Islāmiyyah, (Qāhirah: Maktabah Wahbah, 2001).

4 Muhammad 'Ābid al-Jābirī, Takwīn al-'Aql al-'Arabī (Bayrūt: Markaz Dirāsah al-Widah al-‘Arabiyyah, 1989).

5 T.J. De Boer, The History of Philosophy in Islam (Richmond: Curson Press, 1994), 28-29. 
pemangkin untuk segala perilaku manusia. ${ }^{6}$

2. Secara kontekstualnya, abad ke 16-18 merupakan era terpenting dalam sejarah keagungan tamadun Islam di Alam Melayu. Hal ini bertepatan dengan teori yang diutarakan oleh S.M. Naqquid al-Attas. Kedatangan Islam ke Alam Melayu tidak berlaku secara sekaligus, tetapi ia ditakdirkan Allah berlaku secara berperingkat-peringkat, yang amat berbeza perkembangan dan kesan keislaman ke atas masyarakat Melayu di dalam setiap peringkat perkembangannya. S.M. Naqquid al-Attas menegaskan bahawa proses pengislaman di Alam Melayu telah melalui tiga zaman yang utama. Pertama, zaman antara tahun 1200-1400 iaitu zaman pengislaman masyarakat Melayu secara zahir dan luaran semata-mata (nominal conversion). Kedua, zaman antara tahun 1400-1700 yang dijelaskan sebagai zaman pengislaman masyarakat Melayu secara zahir dan batin yang antara kesannya adalah tersebarnya ilmu pengetahuan yang cukup menggalakkan dalam pelbagai bidang Pengajian Islam. Ketiga, zaman antara tahun $1700 \mathrm{ke}$ atas, yang digambarkan sebagai zaman penerusan idea daripada kedua, dan kemudiannya telah terganggu dengan kedatangan kuasa barat di Tanah Melayu. ${ }^{7}$ Justeru, berasaskan kepada teori ini, kita dapat mengetahui zaman Aceh iaitu di akhir zaman kedua dan ketiga merupakan zaman keagungan tamadun MelayuIslam.

\section{Latar Belakang Sejarah Alam Melayu Abad 16-18}

Sebagai asas logistik, era pada abad ke 16-18 ini dicirikan dengan beberapa perkembangan yang memangkinkan lagi kelahiran konsep Fiqh Alam Melayu. Antara perkembangan ini;

6 Muhammad Abu Bakar, "Pandangan Dunia, Ideologi dan Kesarjanaan: Islam, Proses Sejarah dan Rekonstruksi Realiti Sosial", dalam Tinta Kenangan, Sumbangan Sempena Persaraan dan Perlantikan Naib Canselor, Profesor Datuk Mohd Taib Osman (Kuala Lumpur, 1993), 307-309.

7 S.M. Naquid al-Attas, Preliminary Statement on a General Theory of the Islamization of the Malay-Indonesian Archipelago (Kuala Lumpur, 1969). 


\section{i) Wujud Budaya Ilmu dan Sistem Tulisan Jawi yang Menjana Perkembangan Ilmu Islam}

Melalui penemuan artifak tertua di Tanah Melayu iaitu Batu Bersurat Terengganu yang bertarikh 22 Februari 1303M, kita dapat mengesan beberapa perkara: ${ }^{8}$

Masyarakat Melayu Terengganu yang mewakili masyarakat Melayu Pantai Timur Tanah Melayu adalah golongan terawal yang memeluk Islam di Alam Melayu. Hal ini bukannya berlaku secara superficial (luaran semata-mata), tetapi turut diperkuatkan dengan pelaksanaan Syariah Islam di dalam kehidupan bermasyarakat. Mereka telah mengamalkan undang-undang Islam secara holistik dalam aspek jenayah, munakahat, muamalah dan politik. Batu Bersurat Terengganu berfungsi sebagai rujukan bagi seorang pembesar dan masyarakat awam Melayu agar setiap pelakuan hidupnya bersesuaian dengan kehendak Islam. ${ }^{9}$ Bagi D.G.E. Hall ${ }^{10}$ sebelum Batu Bersurat Terengganu ini wujud, perundangan Islam telah bertapak lebih daripada seratus sebelumnya. Lebih penting lagi, penulisnya adalah seorang yang terpelajar dalam bidang keagamaan Islam, kerana mengetahui agama Islam dan ilmu Usul al-Fiqh secara holistik. Apa yang jelas, mereka mengetahui intipati isu kefahaman akidah Islam dan mekanisme pelaksanaan hukum Islam. ${ }^{11}$

Batu Bersurat Terengganu ini menjadi mercu tanda penciptaan tulisan Jawi dalam dunia intelektual Alam Melayu. Merujuk kepada asal usul penciptaan dan penggunaan tulisan Jawi dalam masyarakat Melayu, kita perlu berterima kasih dengan sumbangan

8 Rahimin Affandi Abd. Rahim, "Batu Bersurat di Terengganu: Satu Tafsiran Terhadap Pelaksanaan Syariah Islam”, Jurnal Fiqh 7 (2010).

9 Abdul Rahman Abdullah, Pemikiran Umat Islam di Nusantara (Kuala Lumpur, 1999), 60-61.

10 D.G.E. Hall, A History of South East Asia (London: St. Martins Press, 1968), 255.

11 Rahimin Affandi Abd. Rahim, "Pengamalan Ilmu Usul al-Fiqh di dalam Sastera Undang-undang Melayu: Satu Analisa”, dalam Muhammad Mokhtar Hassan (ed.), Kesusasteraan dan Undangundang (Universiti Malaya: Penerbitan Akademi Pengajian Melayu, 2003), 158-179. 
ulama Melayu Islam terawal yang telah mengasaskan dan memperkayakan Bahasa Melayu ${ }^{12}$ dalam bentuk tulisan Jawi, yang dijadikan sebagai alat untuk mengembangkan keilmuan Islam. ${ }^{13}$ Fenomena yang mengambilkira elemen tempatan dalam bentuk memilih bahasa tempatan sebagai medium untuk penyebaran ilmu agama telah dilakukan oleh sarjana Islam di kebanyakan dunia Islam, seperti penciptaan tulisan Urdu di India dan tulisan Parsi di Iran yang berteraskan kepada bahasa Arab dari segi bentuknya dengan sedikit pengubahsuaian. ${ }^{14}$

\section{ii) Wujud Kekuatan Sosio-Politik dan Keilmuan Islam yang Dimainkan Kerajaan Aceh}

Di peringkat global pada era pasca Perang Salib, ummah Islam memperjuangkan idealism teori kerajaan Dār al-Islām dan Dār al-Harbī. Sememangnya bangsa Arab lebih terkehadapan daripada bangsa Eropah dalam menguasai jalan dagang antara Timur dan Barat. ${ }^{15}$ Oleh itu, mereka lebih memahami bagaimana sistem politik-perdagangan dunia secara makro dijalankan. ${ }^{16} \mathrm{Hal}$ ini kemudiannya dikonstruk oleh sarjana politik Islam dalam teori politik Islam. Sejak awal lagi, pedagang barat terpaksa bergantung kepada maklumat daripada bangsa Arab untuk mengetahui realiti dunia Alam Melayu. ${ }^{17}$ Hasilnya, sejak awal lagi kedua bangsa ini maklum terdapat dua blok kuasa besar dunia berasaskan kekuatan agama dan ketenteraan; blok Islam dan bukan Islam

12 Amran Kasimin, Perbendaharaan Kata Arab dalam Bahasa Melayu (Bangi, 1987).

13 Omar Awang, "The Major Arabic Sources Which Determined the Structure of Islamic Thought in the Malay Archipelago Before the Nineteenth Century A.D in The Field of Law Theology and Sufism" Islamika 1 (1981).

14 Omar Awang, "The Terengganu Inscription as the Earliest Known Evidence of the Finalisation of the Jawi Alphabet," Federation Museums Journal 25 (1980).

15 Anthony Reid, "An Age of Commerce in Southeast Asian History," Modern Asian Studies 24 (1990).

16 Hussain Ali Tahtooh, "Commercial Relations Between the Arab World and India (3th And $4^{\text {th }} / 9^{\text {th }}$ and $10^{\text {th }}$ Centuries" (Tesis $\mathrm{PhD}$, University of St. Andrews Scotland, 1987).

17 Thomas Braddel, "On the History of Achene", The Journal of the Indian Archipelago and Eastern Asia 5 (1851), 18. 
(diwakili oleh Portugis / Kristian yang memusuhi blok Islam). Di kalangan blok Islam pula, terdapat beberapa blok; (i) Turki yang memegang status khalifah Islam dan kuasa ketenteraan ${ }^{18}$; (ii) Mughal dan Saljuk yang juga memiliki kuasa ketenteraan yang kuat; (iii) Timur Tengah menjadi pusat keilmuan Islam dan (iv) blok Alam Melayu ${ }^{19}$ yang memerlukan naungan daripada blok i,ii dan iii. Sebagai contoh, isu penjajahan Portugis di Melaka telah dibincangkan secara meluas oleh pemimpin umat Islam dalam musim haji di Mekah.

\section{iii) Versi Fiqh Alam Melayu}

Sejak awal lagi ulamak Melayu memahami Fiqh Islam di Alam Melayu perlu mempunyai ciri-ciri konsep fiqh semasa. Lebih penting lagi, ia telah meletakkan asas terpenting (formatif) bagi sistem Fiqh Islam itu sendiri. Walaupun konsep fiqh semasa (tempatan) hanya dikenali pada abad 20, tetapi asasnya telahpun wujud sejak zaman awal Islam di Alam Melayu khususnya pada abad 16-18. Hal ini terbukti apabila sebahagian daripada intipati konsep ini telah pun wujud dalam tempoh masa yang lebih awal di Alam Melayu. Tambahan pula, saranan ini mempunyai precedent di dalam sejarah pembinaan hukum Islam. Sebagai contoh, walaupun Imam Shafii telah digelar sebagai arkitek utama yang mencipta ilmu Usul al-Fiqh, tetapi pada dasarnya kaedah ilmu ini telah wujud dan diamalkan oleh sesetengah fuqaha dalam tempoh masa yang lebih awal lagi. Sebaliknya sumbangan yang dimainkan oleh Imam Shafii adalah untuk menerangkan dan menyusunnya secara sistematik berbanding dengan fuqaha sebelumnya. ${ }^{20}$

18 A.C.S. Peacock, "The Economic Relationship Between the Ottoman Empire and Southeast Asia in the Seventeenth Century", Proceedings of the British Academy; From Anatolia to Aceh, Ottoman, Turks and Southeast Asia (Oxford: Oxford University Press, 2015), 63-87.

19 Shaharil Talib, "The Asiatic Archipelago: History Beyond Boundaries", JATI 3 (1997), 132-135.

20 N.J. Coulson, A History of Islamic Law (Edinburgh, 1964), 53 \& 55. 


\section{KONSTRUK FIQH ISLAM DI ALAM MELAYU ABAD KE 16-18}

Fiqh Islam versi Alam Melayu sejak awal adalah berasaskan kepada elemen ontologi, epistemologi dan aksiologi yang khusus. Ia kemudiannya menjadi disiplin baku yang diteruskan penulisannya sehingga pada zaman moden. Mengikut perspektif Islam, proses pembangunan suatu tradisi ilmu perlu bergantung kepada sumber tradisi (turāth) yang menjadi asas penting. Tradisi ini kemudiannya perlu berinteraksi dengan realiti tempatan mengikut zaman; realiti Alam Melayu sehingga mewujudkan tradisi ilmu baru iaitu Manhaj Islam Alam Melayu. Di sini terletak keunggulan Islam, bila mana sifat ummah Islam sangat dinamik dan sentiasa terbuka dengan perubahan yang menjadi lumrah dalam kehidupan. Ini bermakna ummah Islam melalui elemen kesinambungan dan perubahan (continuity dan changing), contohnya seperti mazhab yang telah dominan kerangka metodologinya akan melalui proses pembaharuan (ișlāh) bagi memperkemaskan lagi kewujudannya. ${ }^{21}$

Sejarah keilmuan dunia mencatatkan bagaimana sesuatu doktrin dapat bertahan lama seandainya ia memenuhi empat syarat utama; pertama, kesahihan logika dan argumen, kedua; menarik perhatian orang untuk diikuti, ketiga; mampu diterapkan terhadap kes yang dihadapi (apllicable) dan keempat; ia mempunyai mekanisme untuk proses islah memperbaharui idea yang lama tanpa meninggalkan asas tradisi yang penting. Jelasnya, keempatempat perkara ini memang dimiliki oleh tradisi Islam Alam Melayu, sehingga mendorongnya untuk kekal sehingga sekarang. ${ }^{22}$ Ia bertentangan sama sekali dengan ulasan negatif yang diberikan oleh sarjana-pentadbir Orientalis di Tanah Melayu, bahawa kononnya hukum Islam tidak mempunyai asas epistemologi yang kukuh. ${ }^{23}$

$21 \quad$ Ismail Raji Faruqi, Tauhid, Kesannya Terhadap Pemikiran dan Kehidupan, terj. Unit Terjemahan Modal Perangsang Sdn. Bhd. (Kuala Lumpur, 2000), 51-55.

22 Amir Mualim, Ijtihad dan Legelasi Muslim Kontemporer (Yogyakarta: UII Press, 2006), ix-xi.

23 Mohd Farhan Abd Rahman, "Undang-Undang Islam dalam Masyarakat Melayu: Analisis Terhadap Bentuk Pemikiran dan Pandangan R.O. Winstedt", Jurnal Fiqh 9 (2012), 87-112. 
Asas tradisi turäth milik warisan Timur Tengah akan sentiasa bertembung dengan pelbagai realiti masalah yang wujud di Alam Melayu. Antaranya seperti masalah bid'ah, budaya feudal sesat yang melanggar asas agama dan sebagainya. Adunan daripada tradisi Timur Tengah dan Alam Melayu kemudiannya melahirkan tradisi dan formula Islam Alam Melayu yang bertepatan dengan realiti budaya tempatan.

\section{i) Ontologi}

Ia mengajar beberapa kefahaman khusus yang berkait dengan aspek ontologi (apa dia - subject matter) Fiqh Islam;

Pertama, penganut Islam adalah mukallaf yang wajib memahami dan mengamalkan Islam di peringkat kognitif, afektif dan psikomotor. Sistem fiqh sejak awal difahami sebagai garis panduan bertindak bagi anggota masyarakat. Bagi memastikan ia sentiasa relevan untuk keperluan zaman dan tempat, maka fuqaha Melayu telah menyediakan panduan fiqh yang tidak memberatkan. Mereka memahami bahawa masyarakat Melayu yang baru menerima Islam sangat memerlukan suatu kerangka fiqh yang cukup berhemah. Atas dasar itu, soal ibadah adalah isu terpenting yang diberikan penekanan utama. Ia perlu bagi memastikan kaedah yang tepat bagi menjalinkan hubungan dengan Allah dapat dijalankan. Langkah ini berjalan seiring dengan ajaran Tauhid yang benar-benar murni tanpa ada elemen syirik dan unsur-unsur bid'ah. Di samping itu, fuqaha Melayu memahami bahawa sistem fiqh ini perlu disesuaikan dengan latar belakang masyarakat tempatan, agar dapat menjawab masalah lokasi terbabit. Atas dasar itu elemen tempatan diterapkan dalam hukum Islam. Hal ini terbukti apabila fuqaha Melayu membahaskan pelbagai masalah yang timbul di dalam masyarakat Melayu dengan bantuan daripada sumber Fiqh Timur Tengah. Dalam lipatan sejarah Fiqh Alam Melayu, kita dapat menemui kupasan fuqaha dalam isuisu merangkumi isu kepenggunaan, kepimpinan wanita dan isu ketatanegaraan. ${ }^{24}$

24 Khalif Muammar Haris, "Ilmu Ketatanegaraan Melayu Abad Ke 19: Kajian Terhadap Karya Raja Ali Haji”, International Journal of the Malay World and Civilization 29, no. 1 (2011), 79-101. 
Kedua, mukallaf Islam perlu mengamalkan world-view kehidupan yang sepatutnya dalam hidup bermasyarakat. Ia terdiri daripada world-view Tauhid, mementingkan budaya ilmu, rationalistik, prinsip societal (sifat kepedulian hidup bermasyarakat) dan world affirmative (dunia sebagai tempat berguna) - mementingkan kepentingan hidup dunia dan akhirat. ${ }^{25}$

\section{ii) Epistemologi (Isu Had dan Sumber Ilmu)}

Seperti mana ditegaskan dengan cukup tuntas oleh S.M. Naquid al-Attas, sumbangan Islamisasi terbesar di Alam Melayu adalah membabitkan soal epistemologi ilmu. ${ }^{26}$ Di dalam kajian ilmiah, terdapat suatu pendekatan yang menetapkan bahawa proses pengkajian yang mendalam terhadap sesuatu hakikat ilmu ataupun disiplin tertentu perlu dilihat kepada aspek epistemologi disiplin tersebut. Hal ini bersesuaian dengan takrif dan ruang lingkup epistemologi yang menyelidik asal usul, sumber, sifat, kaedah dan had sesuatu ilmu tersebut. ${ }^{27}$ Bagi menerangkan tentang elemen epistemologi ilmu yang diperkenalkan oleh sarjana abad ke-16 ini, kita perlu melihat kepada beberapa perkara di dalam kupasan fuqaha awal.

\section{a) Persoalan Asal Usul dan Sumber Hukum Islam}

Secara asasnya, syariah Islam berpunca daripada kehendak Allah yang Maha Berkuasa secara mutlak berasaskan kepada konsep Tauhid Uluhiyyah dan Rububiyyah. Dalam konsep Tauhid Rububiyyah, Allah yang berkuasa penuh dalam mencipta, mendidik dan menjaga umat manusia dengan menganugerahkan

25 Rahimin Affandi Abd Rahim, "Penguasaan Ilmu Pengetahuan", dalam Mahmood Zuhdi Abd Majid (ed.), Islam Hadhari: Pendekatan Pembangunan Peradaban (Kuala Lumpur: YADIM, 2007), 235328.

26 S.M. Naquid al-Attas, The Oldest Known Malay Manuscript: A 16th Century Malay Translation of the Aqa'id of al-Nasafi (Kuala Lumpur: Penerbit Universiti Malaya, 1988), 53-54.

27 Fadzulullah Shuib, Kecermelangan Ilmu dalam Sejarah dan Tamadun Islam (Kuala Lumpur, 1995), 33. 
syariahnya yang lengkap. ${ }^{28}$ Kesempurnaan syariah ini diturunkan adalah bagi tujuan membimbing dan mengurangkan sifat-sifat kelemahan asasi yang dimiliki oleh manusia. Berikutnya, apa yang lebih penting adalah konsep membantu kelemahan diri manusia telah dilengkapkan lagi dengan bantuan kerasulan yang berperanan mengajar dan mengasaskan perundangan yang sangat praktikal untuk umat manusia bersesuaian dengan konteks zamannya. Jalinan yang erat antara wahyu Allah dan perutusan kerasulan ini telah menjadi sumber yang paling asas di dalam perundangan Islam, yang dikenali sebagai sumber wahyu, ${ }^{29}$ terkandung di dalamnya semua perkara dan nilai asas Islam yang amat diperlukan oleh umat manusia sehingga kiamat. ${ }^{30}$

Di samping sumber wahyu ini, syariah juga mengakui peranan dan potensi akal manusia di dalam menentukan persoalan hukum Islam berpandukan garis panduan yang termaktub di dalam sumber wahyu. Hal ini berasaskan pengakuan dan tindakan Rasulullah sendiri yang menerapkan pendekatan menghidupkan penggunaan akal terpimpin di dalam pendidikan perundangannya yang difahami secara langsung oleh para sahabat. Kebenaran dan pengakuan terhadap kemampuan fungsi akal ini kemudiannya telah dikembangkan lagi oleh fuqaha dengan lebih mendalam di dalam penulisan Usul al-Fiqh yang mengakui sumber hukum kedua selepas sumber wahyu (naqlī) adalah sumber ijtihad ('aqlī). Hasilnya, fuqaha telah melanjutkan perbincangan berkaitan dengan peranan akal di dalam beberapa bahagian yang khusus, pertamanya; penerangan yang meneliti tentang sumber hukum tambahan lain yang timbul daripada sumber hukum aqli ini. Antaranya adalah qiyās, ijmā', istihsān, mașlaḥah, siyāsah shar 'iyyah, mașālih mursalah dan sebagainya. ${ }^{31}$

Namun begitu, penggunaan akal perlu dikawal sepenuhnya agar ia tidak terlalu bebas dan statik. Pendekatan ini boleh dilihat

28 Ramli Awang, Tasawwur Rabbani Menurut al-Quran dan al-Sunnah (Kuala Lumpur, 1997), 179-187.

29 Mahmood Zuhdi Abd. Majid, Sejarah Pembinaan Hukum Islam (Kuala Lumpur, 1992), 39-40.

30 Lihat Hashim Musa, "Islam: An Overview in History and Contemporary World", Jurnal AFKAR 2 (2001), 1-25.

31 Umar Jah, "The Importance of Ijtihad in the Development of Islamic Law", Journal of Comparative Law 7 (1977), 31-40. 
dari kupasan fuqaha yang menyentuh persoalan ruang lingkup, objektif dan fungsi sistem perundangan Islam. Kebanyakan fuqaha membahagikan hukum Islam kepada bidang ibadah dan mu'amalah. Bidang ibadah serta strukturnya secara khusus diterangkan di dalam sumber wahyu secara terperinci dan ia tidak membuka ruang yang luas untuk akal manusia campur tangan. Manakala bidang mu'amalah yang pada kebiasaannya banyak bergantung kepada keadaan hidup yang sentiasa berubah telah memberi ruang yang luas untuk akal manusia berfikir berkaitannya. Oleh itu, soal-soal yang berkaitan dengan hubungan sesama umat manusia banyak diserahkan kepada umat Islam untuk memikir dan menentukannya sendiri. Namun begitu, penentuan akal manusia ini perlu berdasarkan kerangka dan landasan yang terdapat di dalam sumber wahyu.

\section{b) Isu Autoriti}

Semua ajaran Islam, khususnya hukum Islam perlu disandarkan pada sumber wahyu dan karya ulama silam. Perkara ini secara langsung mengajar masyarakat Melayu bahawa:

Pertama, sumber ilmu perlu berasaskan sumber yang boleh dipertanggungjawabkan, bukannya berasaskan sumber dongeng dan mitos. Lebih praktikal lagi, idea dan ilmu Islam daripada Timur Tengah telah diterjemahkan ke dalam bahasa Melayu (dalam bahasa yang mudah difahami) dan diresapi dengan unsurunsur tempatan Alam Melayu. Ia bagi mengajar masyarakat Alam Melayu yang baru memeluk Islam bagaimana memahami akidah (elemen kognitif) dan mengamalkan Islam dalam kehidupan seharian.

Kedua, kandungan asas ilmu Islam diambil dan diterjemahkan daripada sumber ulama Timur Tengah bagi memastikan transmisi ilmu yang paling berautoriti diperolehi. Lebih tepat lagi, Kitab Jawi yang dihasilkan oleh ulama Melayu menjadi pengantara untuk idea Islam Timur Tengah diperolehi oleh masyarakat Melayu. ${ }^{32}$ Sebagai contoh, sanad ilmu Islam daripada autoriti

32 Faudzinaim Hj Badaruddin, "Peranan Kitab Jawi Tasawuf sebagai Medium Transmisi Ilmu Islam kepada Masyarakat Melayu Nusantara", International Journal of Islamic Thought 1 (2012), 1925. 
muktabar seperti Imam al-Ghazālī diterima oleh dua generasi ulama Haramayn yang diperturunkan kepada pelajar Alam Melayu. ${ }^{33}$ Pada abad ke-17, sanad Aḥmad al-Qusyasī dan Ibrāhim al-Kuranī telah diperturunkan kepada Abdul Rauf Singkel dan Muhammad Yusuf al-Makassar. Pada abad ke-18 pula, sanad Abū Țāhir Ibrāhim al-Kuranī, Muḥammad Ḥayya al-Sindī dan Muhammad 'Abd al-Karīm al-Sammanī diperturunkan kepada Abdul Samad al-Palembani, Muhammad Arshad al-Banjari dan Daud Abdullah al-Patani. ${ }^{34}$ Lebih khusus lagi, hasil penelitian lanjut kita mendapati sumber rujukan Kitab Turath Timur Tengah yang kerap digunakan adalah daripada jenisnya yang paling muktabar pada masa tersebut. Ia telah melalui proses tapisan dan pemurnian (al-Tanqīh Madhhab) yang cukup ketat bagi memastikan hanya pandangan mazhab Shafii yang terpilih yang diterima pakai. ${ }^{35}$ Contohnya;

1. Minhāj al-Țālibin wa 'Umdah al-Muftīn

2. Manhāj al-Ṭullāb wa Fath al-Wahhāb

3. Al-Anwār li A'māl al-Abrār

4. Fatḥ al-Jawwād Syarḥ al-Irsyād

5. Mughnī al-Muḥtāj ilā Ma'rifah Ma'ānī Alfāz al-Minhāj

6. Tuhfah al-Muhtāj bi Syarḥ al-Minhāj

\section{c) Pergantungan Kepada Formula Mazhab}

Konstruk ilmu perlu bergantung kepada mazhab Ahl al-Sunnah wa al-Jamaah. Tindakan berpegang kepada mazhab ASWJ ini dilaksanakan bukan secara sewenangnya. ${ }^{36}$ Secara umum, mazhab

33 Nurman Said, "The Significance of al-Ghazali and His Works for Indonesian Muslim: A Preliminary Study", Studia Islamika 3, no. 3 (1996), 21-42.

34 Azra Ayumardi, "The Significance of Southeast Asia (The Jawah World) for Global Islamic Studies: Historical and Comparative Perspectives", Kyoto Bulletin of Islamic Area Studies 8 (2015), 7677.

35 Jamalluddin Hashim, "Metode Penulisan Fiqh oleh Nur al-Din alRaniri dalam Kitab Sirat Al-Mustaqim”, Jurnal Fiqh 6 (2009), 267298.

36 Luqman Abdullah, "Bermazhab dan Fanatik Mazhab: Satu Sorotan dalam Kerangka Amalan Bermazhab Syafii Masyarakat Melayu", Jurnal Fiqh 4 (2007), 103-118. 
merupakan paradigma berfikir mengikut world-view dan kaedah syariah yang diasaskan oleh fuqaha tertentu. Ia lahir daripada tradisi Islam sendiri dan merupakan kemuncak dari satu proses pembentukan world-view yang panjang. ${ }^{37}$

\section{d) Gaya Persembahan Kitab Jawi}

Buat pertama kalinya, melalui Kitab Jawi masyarakat Alam Melayu didedahkan dengan kaedah penulisan ilmiah yang dapat menjana rasionalism. Ia sangat berbeza dengan karya Melayu sebelum Islam yang berteraskan unsur mitos. Hashim Musa telah membuat perbandingan antara maklumat dalam sastera Melayu warisan Hindu-Buddha dengan Kitab Jawi zaman Islam daripada dua petikan yang berikut: ${ }^{38}$

Hikayat Si Miskin atau Marakarma (zaman Hindu-Buddha);

"Di negeri Anta Beranta memerintah Maharaja Indera Dewa. Di sana tinggal si-Miskin dan isterinya yang sangat papa. Kedua mereka dahulu raja di Indera Kayangan tetapi kerana sumpah Betara Indera terbuang ke bumi. Mereka dinyahkan dengan tongkat dan batu dari istana, kampung dan pasar. Untuk hidup mereka terpaksa makan pucuk tanaman atau ketupat dan tebu yang mereka ambil dari timbunan sampah di tepi jalan. Setelah isteri Si-Miskin mengandung selama tiga bulan dia mengidam buah mempelam dari kebun raja. Raja Maha Indera Dewa telah memperkenankan Si-Miskin mengambilnya. Tiga bulan kemudian isterinya mengidam buah nangka dari kebun raja yang juga diperkenankan oleh Raja. Dia melahirkan seorang anak yang elok parasnya. Anak ini dinamakan Marakarma sebab dia

37 Rahimin Affandi Abd. Rahim, "Pengamalan Ilmu Usul al-Fiqh di dalam Sastera Undang-undang Melayu: Satu Analisa", dalam Muhammad Mokhtar Hassan (ed.), Kesusasteraan dan Undangundang (Universiti Malaya: Penerbitan Akademi Pengajian Melayu, 2003), 332-265.

38 Rozita Che Rodi, "Konsep Kebenaran Ilmu dalam Bahasa Melayu Berpaksikan Pandangan Islam yang Sejagat", International Journal of the Malay World and Civilization 2, no. 1 (2014), 6. 
lahir dalam kemiskinan. Pada waktu menggali tanah untuk mendirikan pondok, SiMiskin telah menjumpai sebuah tajuk penuh emas. Sesudah mandi dia memuja dewa untuk mencipta kota dalam hutan. SiMiskin memerintah kota itu yang diberi nama Puspa Sari dengan gelaran Maharaja Indera Angkasa dan isterinya bergelar Ratna Dewi."

'Aqā’id al-Nasafī (terjemahan) (zaman Islam); ${ }^{39}$

"Maka segala perkara yang menghasilkan ilmu bagi makhluqat itu tiga perkara: suatu pancaindera yang lima, kedua khabar sadiq (yakni berita benar), ketiga akal. Maka pancaindera yang lima itu suatu pendengar, kedua penglihat, ketiga pencium, keempat perasa lidah, kelima perasa tubuh. Bermula dengan segala sesuatu pancaindera yang lima, daripadanya diketahui atas yang ditentukan ia baginya dengan dia. Bermula khabar sadiq itu atas dua bagi juga: suatu dari dua itu khabar mutawatir, iaitu khabar yang thabit pada segala lidah kaum tiadakan dapat pada budi muafakat mereka atas dusta. Iaitu tahu dengan dibicara diketahui adanya, iaitu menghasilkan bagi ilmu dharuri, seperti tahu akan segala raja-raja yang telah sunyi pada segala masa yang telah lalu, dan segala negeri yang jauh."

Kitab Jawi yang menjadi asas tradisi Islam ini mempunyai beberapa bentuk persembahan, iaitu;

1. Bahasanya mudah difahami. Sekiranya rumit, ia bakal dihuraikan oleh ulama khusus. Sebahagian Kitab Jawi ini telah dibuat dalam bentuk prosa biasa dan ada dalam bentuk nazam (puisi dan syair). Tujuannya adalah bagi menarik minat pembaca dan mudah untuk diingati.

2. Ia dikonstruk agar dapat menjana pembacaan, pemikiran dan wacana yang lebih proaktif daripada pembaca, ada matan dan syarah (berisi komentar sendiri ataupun daripada guru yang mengajar). Maksudnya, ia dikonstruk bagi memastikan sifat jumud tidak berlaku bila mana bahagian matan (isi utama)

39 Naquid al-Attas, The Oldest Known Malay Manuscript, 53-54. 
akan disyarah bersama catatan daripada pembaca. Secara langsung ia mengajar pembaca membaca, berfikir dan memberi komentar dalam bahagian syarahnya.

3. Memperkenalkan gaya penulisan ilmiah. Ia merangkumi teknik penulisan kitab dengan gaya penulisan, penerangan dan penghuraian, kemusykilan dan penyelesaian masalah. Lebih menarik lagi, usaha penyaringan dan pemindahan ilmu daripada bahasa Arab ke bahasa Melayu dilakukan dengan baik. $^{40}$

4. Ia terbuka untuk difikirkan dan dilakukan penambahbaikan yang berterusan. Mengikut Hashim Musa, sekiranya dilakukan perbandingan antara kandungan Kitab Jawi dengan sastera hikayat, buat pertama kalinya masyarakat Melayu didedahkan dengan pengetahuan ilmu peringkat tinggi yang menekankan kepada soal autoriti idea yang dibawa. ${ }^{41}$

5. Setiap pengarang Kitab Jawi akan memasukkan nama pengarangnya sesuai dengan konsep tanggungjawab Islam yang menuntut nama pengarang dan sanad sandaran ilmunya dinyatakan. ${ }^{42}$

6. Mengajar penganut Islam agar menjadi pengikut yang bertamadun (mementingkan isu peraturan). Ia juga mengajar supaya berhati-hati dalam elemen kognitif, afektif dan

$40 \quad$ Hadenan Towpek, "Kaedah Penulisan Syeikh Daud Al-Fatani dalam Furu Al-Masail dengan Tumpuan kepada Bab Muamalat", Jurnal Fiqh 10 (2013).

41 Hashim Musa, "Pelestarian Bahasa Melayu sebagai Bahasa Utama dalam Persuratan dan Pembudayaan Ilmu, Sains dan Teknologi di Rantau Ini", International Journal of the Malay World and Civilization 2, no. 2 (2014), 3-19.

42 Rahimin Affandi Abd. Rahim, "Ulama dan Paradigma Menangani Kebudayaan Melayu, dalam Hashim Awang", Othman Yatim dan Nor Azita Che Din (ed.), Wacana Budaya (Kuala Lumpur: APMUM, 2006), 55-80. 
psikomoto yang tertakluk kepada garis panduan Islam yang khusus. ${ }^{43}$

Melalui versi fiqh Alam Melayu seperti karya Nurudin Raniri iaitu Siratal Mustaqim, kita dapat mengesan bagaimana tokoh ini menetapkan paradigma asas ilmu Islam terawal perlu mengandungi elemen-elemen ini: (1) falsafah Tauhid; (2) pegangan kepada Mazhab ASWJ; (3) asas autoriti; (4) gaya persembahan dan (5) elemen epistemologi. Oleh kerana itu, kitab ini menjadi rujukan utama dan ditahqiq oleh beberapa orang ulama Melayu yang lain. Skop perbahasan kitab ini membincangkan isu yang timbul dalam masyarakat Alam Melayu yang dijawab dengan formula Timur Tengah dan disesuaikan dengan realiti tempatan Alam Melayu. Lebih menarik dalam konteks fiqh, skop perbahasan di zaman terkemudian telah diperluaskan. Sekiranya Nurudin hanya menyentuh isu ibadat semata-mata, ulama Alam Melayu selepasnya telah memperluaskan skop perbahasan kepada bidang muamalat dan selainnya yang lebih luas. ${ }^{44}$

Berbanding dengan formula Timur Tengah, paradigma fiqh Alam Melayu lebih unik kerana;

1. Fleksibel dan menerima 'urf Alam Melayu (sistem budaya) yang bersifat sederhana dan mesra alam. ${ }^{45}$

2. Terbuka kepada penambahbaikan yang berterusan. Ulama Melayu memahami struktur ajaran Islam yang terbahagi kepada ibadah (bersifat kekal) dan muamalah (fleksibel). Atas dasar itu, usaha penerusan daripada tradisi awal membabitkan isu muamalah dilakukan dengan cukup berkesan. Antara penambahbaikan yang terbabit adalah usaha membasmi isu khurafat dan bid'ah yang tetap wujud dalam masyarakat Melayu. Ia termasuk pendekatan neo-sufism yang merapatkan sufi dengan syariah dan terlibat aktif dengan aktiviti masyarakat.

43 Idris Zakaria, "Islam dan Amalan Tolenrasi di Nusantara", dalam Jaringan Dakwah Malaysia Indonesia (Bangi: Jabatan Pengajian Dakwah dan Kepimpinan, UKM dan Universitas Muhammadiyah Sumatera Utara (UMSU), 2003), 150-164.

44 Mohd Anuar Ramli, "Mazhab Syafii dalam Pengajian Syariah di Malaysia: Satu Analisis", Jurnal Fiqh 4 (2007), 39-76 .

45 Mohd Anuar Ramli, "Bias Gender dalam Masyarakat Muslim: Ajaran Islam dengan Tradisi Tempatan", Jurnal Fiqh 7 (2010). 
3. Kegiatan ilmu Islam tidak dihadkan kepada ilmu agama semata-mata bahkan divariasikan dalam beberapa bidang yang lain seperti kepenggunaan, ${ }^{46}$ perubatan, ${ }^{47}$ muamalah, maqasid ${ }^{48}$ pertukangan, astronomi Islam ${ }^{49}$ dan sebagainya. Agak menarik apabila terdapat banyak kearifan daripada tempatan Melayu (kepandaian orang Melayu berinteraksi dengan persekitaran) turut diterapkan dengan nilai-nilai Islam. Hal ini menyebabkan sebahagian besar daripada pola cita dan pola budaya Melayu diresapi dengan nilai-nilai Islam yang kekal sehingga sekarang.

4. Ulama dijadikan sebagai penasihat kepada raja-raja Melayu bukan hanya dalam aspek upacara rasmi bahkan dilanjutkan kepada peringkat dasar terpenting negara. Hal ini agak berbeza dengan realiti penglibatan ulama dalam tradisi Timur Tengah silam. Selepas tamatnya pemerintahan Khalifah al-Rasyidin, kebanyakan ulama salaf mengambil dua pendekatan utama; mendekati pemerintah semasa dan menjauhkan diri daripada terlibat dengan pihak kerajaan. Rata-rata ulama salaf yang hebat seperti Abu Hanifah dan Shafi'i enggan terlibat dalam urusan rasmi pemerintah. Sebaliknya mereka lebih cenderung melibatkan diri dalam aktiviti pengajaran dan pembangunan keilmuan Islam.

\section{KESIMPULAN}

Sebagai rumusan akhir, dapat disimpulkan bahawa kedatangan Islam merupakan episod terpenting dalam sejarah Alam Melayu. Seperti mana Islam telah mengubah world-view masyarakat

46 Hadenan Towpek, "Aspects of Economic Consumption in Malay Clasiccal Literature According to Sheikh Daud al-Fatani”, Labuan E-Journal of Muamalat and Society 6 (2012), 30-36.

47 Mohd Asmadi Yakob, "Gaya Hidup Sihat Melalui Pemakanan: Kajian Terhadap Penulisan Ulama-ulama Nusantara dalam Kitab Jawi" (Hasil Kajian daripada Geran Dana Penyelidikan UiTM, 2010).

48 Muammar Ghaddafi Hanafiah, "Nilai-Nilai Maqasid al-Shariah dalam Kitab al-At'imah: Tinjauan dalam Pemikiran al-Shaykh Muhammad Arsyad Banjari (1710-1812M)", International Journal of the Malay World and Civilization 3, no. 3 (2013), 29-38.

49 Baharudin Zainal, "Grafisejarah Falak Rumpun Melayu Melalui Kajian Teks Utama”, Menemui Matematik 32, no. 1 (2010), 57-74. 
Arab, hal yang sama berlaku di Alam Melayu. Terpenting sekali, proses Islamisasi yang diikuti dengan perkembangan ilmu telah melahirkan dan menjana paradigm keilmuan yang berdaya maju untuk masyarakat Alam Melayu. Hal ini telah dijelaskan dengan panjang lebar di dalam kajian ini dengan merujuk khusus kepada versi Fiqh Alam Melayu. Asas tradisi yang diletakkan oleh ulama Islam abad ke 16-18 telah menjadi asas formula Islam Alam Melayu sehingga sekarang.

\section{BIBLIOGRAFI}

Abdullah Munsyi. Kisah Pelayaran Abdullah ke Kelantan dan Judah. Disusun oleh Kassim Ahmad. Kuala Lumpur: Fajar Bakti, 1981.

Abdul Halim El-Muhammady. "Ikhtilaf and It's Development in Malaysia." International Islamic University Law Journal 2, no. 2 (1992).

Abdul Rahman Abdullah. Pemikiran Umat Islam di Nusantara. Kuala Lumpur, 1999.

Amran Kasimin. Perbendaharaan Kata Arab dalam Bahasa Melayu. Bangi, 1987.

Amir Mualim. Ijtihad dan Legelasi Muslim Kontemporer. Yogyakarta: UII Press, 2006.

Amirul Hadi. Islam and State in Sumatera: A Study of Seventeenth Aceh. Leiden: E.J.Brill, 2004.

Anthony Reid. "An Age of Commerce in Southeast Asian History". Modern Asian Studies 24 (1990).

Azra Ayumardi. "The Significance of Southeast Asia (The Jawah World) for Global Islamic Studies: Historical and Comparative Perspectives". Kyoto Bulletin of Islamic Area Studies 8 (2015).

A.C.S. Peacock. "The Economic Relationship Between the Ottoman Empire and Southeast Asia in the Seventeenth Century". Proceedings of the British Academy; From Anatolia to Aceh, Ottoman, Turks and Southeast Asia. Oxford: Oxford University Press, 2015. 
Baharudin Zainal. "Grafisejarah Falak Rumpun Melayu Melalui Kajian Teks Utama”. Menemui Matematik 32, no. 1 (2010).

Boxer, C.R. "A Note on Portuguese Reactions to the Revival of the Red Sea Spice Trade and the Rise of Atjeh, 1540-1600". Journal of Southeast Asian History 10, no. 3 (1969).

Charles Tisdall. "Ideas of Mohammedan Malaya." The Missionary Review of the World v. xxxiv (1916).

Coulson, N.J. A History of Islamic Law. Edinburgh, 1964.

D.G. E. Hall. A History of South East Asia. London: St. Martins Press, 1968.

Ermy Azziaty Rozali. "Aceh-Ottoman Relation In Bustan A-Salatin". Mediterranean Journal of Social Science 5, no. 29 (2014).

Fadzulullah Shuib. Kecermelangan Ilmu dalam Sejarah dan Tamadun Islam. Kuala Lumpur, 1995.

Faudzinaim Badaruddin. "Peranan Kitab Jawi Tasawuf sebagai Medium Transmisi Ilmu Islam kepada Masyarakat Melayu Nusantara". International Journal of Islamic Thought 1 (2012).

Hadenan Towpek. "Aspects of Economic Consumption in Malay Clasiccal Literature According to Sheikh Daud al-Fatani". Labuan E-Journal of Muamalat and Society 6 (2012).

"Kaedah Penulisan Syeikh Daud al-Fatani dalam Furu Al-Masail dengan Tumpuan kepada Bab Muamalat". Jurnal Fiqh 10 (2013).

Hallaq. "Ifta and Ijtihad in Sunni Legal Theory: A Development Account". Islamic Legal Interpretation: Muftis and Their Fatwas. Cambridge: Harvard University Press, 1996.

Hashim Musa. Merekonstruksi Tamadun Melayu Islam: Ke Arah Pembinaan Sebuah Tamadun Dunia Alaf Baru. Kuala Lumpur: APMUM, 2001. . "Islam: An Overview in History and Contemporary World". Jurnal AFKAR 2 (2001). 
- "Pelestarian Bahasa Melayu sebagai Bahasa Utama dalam Persuratan dan Pembudayaan Ilmu, Sains dan Teknologi di Rantau Ini". International Journal of the Malay World and Civilization 2, no. 2 (2014).

Hussain Ali Tahtooh. "Commercial Relations Between the Arab World and India (3th And $4^{\text {th }} / 9^{\text {th }}$ And $10^{\text {th }}$ Centuries)" (Tesis Phd, University of St. Andrews, Scotland, 1987).

Idris Zakaria. "Islam dan Amalan Tolenrasi di Nusantara". Dalam Jaringan Dakwah Malaysia Indonesia. Bangi: Jabatan Pengajian Dakwah dan Kepimpinan, UKM dan Universitas Muhammadiyah Sumatera Utara (UMSU), 2003.

Ingrid Saroda Mitrasing. "The Age of Aceh and the Evolution of Kingship 1599-1641" (Tesis Ph.D, University Of Leiden. 2011).

Imam Syaukani. Rekonstruksi Epistemologi Hukum Islam di Indonesia. Jakarta: PT Raja Grafindo Persada, 1999.

Ismail Raji Faruqi. Tauhid, Kesannya Terhadap Pemikiran dan Kehidupan. Terj. Unit Terjemahan Modal Perangsang Sdn Bhd, Kuala Lumpur, 2000.

Jajat Burhanudin. "The Dutch Colonial Policy on Islam: Reading The Intellectual Journey of Snouck Hurgronje". Al-Jami'ah: Journal of Islamic Studies 52, no. 1 (2014).

Jamalluddin Hashim. "Metode Penulisan Fiqh oleh Nur al-Din al-Raniri dalam Kitab Sirat al-Mustaqim". Jurnal Fiqh 17 (2009).

Khalif Muammar Haris. "Ilmu Ketatanegaraan Melayu Abad Ke19: Kajian Terhadap Karya Raja Ali Haji”. International Journal of the Malay World and Civilization 29, no. 1 (2011).

Luqman Abdullah. "Bermazhab dan Fanatik Mazhab: Satu Sorotan dalam Kerangka Amalan Bermazhab Syafii Masyarakat Melayu". Jurnal Fiqh 4 (2007).

Louay M. Safi. Truth and Reform: Exploring the Pattern and Dynamics of Historical Change. Kuala Lumpur: Open Press, 1998. 
Mahmood Zuhdi Ab. Majid. Sejarah Pembinaan Hukum Islam. Kuala Lumpur: Penerbit Universiti Malaya, 1992.

. "Hukum Islam Semasa bagi Masyarakat Malaysia yang Membangun". Dalam Hukum Islam Semasa bagi Masyarakat Malaysia yang Membangun. Kuala Lumpur: Akademi Pengajian Islam Universiti Malaya, 1999.

Mohd Anuar Ramli. "Bias Gender dalam Masyarakat Muslim: Ajaran Islam dengan Tradisi Tempatan". Jurnal Fiqh 7 (2010).

. "Mazhab Syafii dalam Pengajian Syariah di Malaysia: Satu Analisis". Jurnal Fiqh 4 (2007).

Mohd Farhan Abd Rahman. "Undang-Undang Islam dalam Masyarakat Melayu: Analisis Terhadap Bentuk Pemikiran dan Pandangan R.O. Winstedt”. Jurnal Fiqh 9 (2012).

Mohd Asmadi Yakob. "Gaya Hidup Sihat Melalui Pemakanan: Kajian Terhadap Penulisan Ulama-ulama Nusantara dalam Kitab Jawi" (Hasil Kajian daripada Geran Dana Penyelidikan UiTM, 2010).

Md. Sidin Ahmad Ishak. The Malays in the Middle East. Kuala Lumpur, 2000.

M. Dien Madjid. "Knitting Togetherness Among The Allied Malay: Aceh-Minangkabau-The Malay Peninsula". Tawarikh: International Journal for Historical Studies 4, no. 1 (2012).

Mohammad Hannan Hassan. "Islamic Legal Thought and Practices of Seventeenth Century Aceh: Treating the Other" (Tesis $\mathrm{PhD}$, Institute of Islamic Studies, Mcgill University, 2014).

Muhammad Abu Bakar. "Pandangan Dunia, Ideologi dan Kesarjanaan: Islam, Proses Sejarah dan Rekonstruksi Realiti Sosial". Dalam Tinta Kenangan, Sumbangan Sempena Persaraan dan Perlantikan Naib Canselor, Profesor Datuk Mohd Taib Osman. Kuala Lumpur, 1993.

Al-Qaraḍāwī, Yūsuf. Madkhal li Dirāsah al-Sharī'ah alIslāmīyyah. Qāhirah: Maktabah Wahbah, 2001. 
Muammar Ghaddafi Hanafiah. "Nilai-Nilai Maqasid al-Shariah dalam Kitab al-At'imah: Tinjauan dalam Pemikiran alShaykh Muhammad Arsyad Banjari (1710-1812M)". International Journal of the Malay World and Civilization 3, no. 3 (2013).

Mujiyono Abdillah. Dialektika Hukum Islam dan Perubahan Sosial: Sebuah Refleksi Sosiologis Atas Pemikiran Ibn Qayyim al-Jauziyyah. Surakarta: Muhammadiyah University Press, 2003.

Muḥammad 'Ābid al-Jābirī. Takwīn al- 'Aql al-'Arabī. Bayrūt: Markaz Dirāsah al-Widah al-'Arabiyyah, 1989.

Muhammad Zainiy Uthman. "Islam, Sains dan Pemikiran Objektif: Suatu Perbandingan Ringkas." Jurnal YADIM 2 (2001).

Nurman Said. "The Significance of al-Ghazali and His Works for Indonesian Muslim: A Preliminary Study". Studia Islamika 3, no. 3 (1996).

Omar Awang. "The Major Arabic Sources Which Determined The Structure of Islamic Thought in the Malay Archipelago Before the Nineteenth Century A.D. in the Field of Law, Theology and Sufism". Islamika 1 (1981).

"The Terengganu Inscription as the Earliest Known Evidence of the Finalisation of the Jawi Alphabet”. Federation Museums Journal 25 (1980).

Rahimin Affandi Abd. Rahim. “The Concept of Ijma' in Islamic Law: A Comparative." The Journal of Hamdard Islamicus 16 (Pakistan, 1993).

. "Pengamalan Ilmu Usul al-Figh di dalam Sastera Undang-undang Melayu: Satu Analisa", Dalam (ed.) Muhammad Mokhtar Hassan. Kesusasteraan dan Undangundang. Universiti Malaya: Penerbitan Akademi Pengajian Melayu, 2003.

. "Ulama dan Paradigma Menangani Kebudayaan Melayu". Dalam (ed.) Hashim Awang, Othman Yatim dan Nor Azita Che Din. Wacana Budaya. Kuala Lumpur: APMUM, 2006. 
. "Penguasaan Ilmu Pengetahuan". Dalam (ed.) Mahmood Zuhdi Abd Majid. Islam Hadhari: Pendekatan Pembangunan Peradaban. Kuala Lumpur: YADIM, 2007.

. "Batu Bersurat di Terengganu: Satu Tafsiran Terhadap Pelaksanaan Syariah Islam”. Jurnal Fiqh (2010).

Ramli Awang. Tasawwur Rabbani Menurut al-Quran dan alSunnah. Kuala Lumpur: al-Hidayah Publication, 1997.

Rozita Che Rodi. "Konsep Kebenaran Ilmu dalam Bahasa Melayu Berpaksikan Pandangan Islam yang Sejagat". International Journal of the Malay World and Civilization 2, no. 1 (2014).

Saleh Faghizadeh. Sosiologi Sosiologi. Terj. Mohd Fauzi Yaacob. Kuala Lumpur: ITNMB, 2004.

Shaharil Talib. "The Asiatic Archipelago: History Beyond Boundaries". JATI 3 (1997).

Snouck Hurgronje. Aceh di Mata Kolonialis. Terj. Ng Singarimbun. Dalam The Achenese. Jakarta: Yayasan Soko Guru, 1985.

S.M. Naquid al-Attas. Preliminary Statement on a General Theory of the Islamization of the Malay-Indonesian Archipelago, Kuala Lumpur. 1969.

. The Oldest Known Malay Manuscript: A 16th Century Malay Translation of The Aqa'id Of Al-Nasafi. Kuala Lumpur: Penerbit Universiti Malaya, 1988.

T.J. De Boer. The History of Philosophy in Islam. Richmond: Curson Press, 1994.

Thomas Braddel. "On the History of Achene". The Journal of the Indian Archipelago and Eastern Asia 5 (1851).

Umar Jah. "The Importance of Ijtihad in the Development of Islamic Law". Journal of Comparative Law (1977).

William Gervase Clarence Smith. "Enunuchs and Concubines in the History of Islamic Southeast Asia". Manusya: Journal of Humanities Special Issue no. 14 (2007). 